\title{
Preparation and characterization of superparamagnetic nickel oxide particles by chemical route
}

\author{
Mohammad Reza Kalaie $^{1}$ - Amir Ali Youzbashi ${ }^{1} \cdot$ Mohammad Ali Meshkot $^{2}$ • \\ Farzad Hosseini-Nasab ${ }^{3}$
}

Received: 1 October 2014 / Accepted: 25 August 2015/Published online: 16 September 2015

(c) The Author(s) 2015. This article is published with open access at Springerlink.com

\begin{abstract}
Homogeneous nickel oxide (NiO) nanoparticles with different sizes between 6 and $30 \mathrm{~nm}$ with narrow size distribution and low agglomeration were synthesized successfully by using different precipitated precursors and heat treatment under certain conditions. Powders were analyzed by different characterization methods. X-ray diffraction patterns revealed that the sizes of nanoparticles synthesized by nickel hydroxide and nickel oxalate precursors are under $10 \mathrm{~nm}$, which are in good agreement with transition electron microscopy and field emission electron microscopy results. According to the vibrating sample magnetometer data, the $\mathrm{NiO}$ nanoparticles with sizes about $6 \mathrm{~nm}$ show superparamagnetic behavior. For superparamagnetic particles, the magnetization at maximum applied field of $20 \mathrm{kOe}$ is $2.46 \mathrm{emu} \mathrm{\textrm {g } ^ { - 1 }}$.
\end{abstract}

Keywords Synthesis - Different precursors - Nickel oxide nanoparticles $\cdot$ Superparamagnetism

Amir Ali Youzbashi

aayouzbashi@gmail.com; a-yuzbashi@merc.ac.ir

Mohammad Reza Kalaie

kalaie@alumni.ut.ac.ir

Mohammad Ali Meshkot

MD@TheConsultants.biz; ali@meshkot.com

Farzad Hosseini-Nasab

f.hosseininasab@modares.ac.ir

1 Materials and Energy Research Center (MERC), P. O. Box 14155-4777, Karaj, Iran

2 Materials Division, The Consultants.biz Consultancy, London, UK

3 Faculty of Electrical and Computer Engineering, Tarbiat Modares University, Tehran, Iran

\section{Introduction}

Magnetic nanoparticles have found widespread applications in modern electronics and other advanced industries due to their morphology and unique physical properties (O'Handley 2000; Gleiter 2000; McHenry and Laughlin 2000; Makhlouf et al. 1997). In magnetic nanoparticles, the surface spins dominate the magnetization due to their lower coordination and uncompensated exchange couplings. This in turn leads to enhanced magnetic properties (Cullity and Graham 2009). Recently, there are many investigations, which show the dependency of coercivity on particle size. With reduction in particle size, the coercivity is increased until a certain maximum value. At such critical points, the multi-domain state changes to a single-domain state. Continuing to further reduce the particle size, the exchange coupling energy decreases and becomes comparable to the thermal energy, KT, which leads to superparamagnetic phenomena (Jeong et al. 2007; Mathew and Juang 2007; Faraji et al. 2010).

More recently, magnetic properties of the transition metal oxide nanoparticles such as $\mathrm{NiO}, \gamma-\mathrm{Fe}_{2} \mathrm{O}_{3}, \mathrm{NiFe}_{2} \mathrm{O}_{4}$, $\mathrm{CoFe}_{2} \mathrm{O}_{4}$, and $\mathrm{MgFe}_{2} \mathrm{O}_{4}$ with antiferromagnetic ordering of magnetic spins have gained renewed interests due to their fascinating properties such as superparamagnetism, enhanced magnetic moments, and field reversal caused by quantum tunneling (Richardson and Milligan 1956; Chen and Zhang 1998). Recently, the effect of spin arrays in the interface of antiferromagnetic (AF) and ferromagnetic (F) materials entitled as exchange bias coupling has been wildly studied, which provides a unidirectional magnetic anisotropy at F/AF interface resulting a hysteresis loop shift. This property has wide application in modern magnetic field spin valve devices. The AF $\mathrm{NiO}$ nanoparticles are good candidate as spin valve devices due to meeting of 
$T_{\mathrm{N}}$ above the room temperature $(523 \mathrm{~K})$, which require an $\mathrm{AF} / \mathrm{F}$ (ferromagnet) interface to produce exchange bias at room temperature (Yi et al. 2007; Karthik et al. 2011). A complex magnetic structure with as many as eight sublattices has been observed in $\mathrm{NiO}$ nanoparticles, in contrast to bulk NiO, which has a simple two-sublattice structure. The different alignments of magnetic moment in different sublattices cause net magnetic properties in the material. It has been earlier suggested that fine particles of $\mathrm{NiO}$ should exhibit weak ferromagnetism or superparamagnetism (Richardson et al. 1991). NiO superparamagnetic particles have many applications such as magnetic data storage, high-sensitivity sensors/giant magnetoresistance (GMR), magnetic resonance imaging (MRI), and drug delivery (Jeong et al. 2007).

Several chemical methods have been used and developed for synthesizing crystalline nickel oxide nanopowders. Traditional chemical synthesis methods used for this purpose have often led to produce agglomerated nanoparticles with sizes larger than $20 \mathrm{~nm}$ (BahariMollaMahaleh et al. 2008; Tao and Wei 2004; Zhou et al. 2006). The aim of the present work was to synthesize modified monodispersed superparamagnetic $\mathrm{NiO}$ nanoparticles with sizes below 10 $\mathrm{nm}$ in a controlled manner through a precipitation-calcination route, as a simple and cost-effective method. In order to control the size and morphology of $\mathrm{NiO}$ particles, three precursors of nickel hydroxide, nickel carbonate, and nickel oxalate were employed, and the role of each was investigated. Calcination temperatures and types of solvent were varying in every precursor. It is worth noting that no surfactant was used in this process in order to reduce the production cost and make it more suitable for mass production.

\section{Experimental}

Analytical grade reagent nickel nitrate $\mathrm{Ni}\left(\mathrm{NO}_{3}\right)_{2} \cdot 6 \mathrm{H}_{2} \mathrm{O}$ was used as a nickel agent in all experiments. Oxalic acid $\left(\mathrm{H}_{2} \mathrm{C}_{2} \mathrm{O}_{4} \cdot 2 \mathrm{H}_{2} \mathrm{O}\right)$, ammonium carbonate $\left[\left(\mathrm{NH}_{4}\right)_{2} \mathrm{CO}_{3}\right]$, and
$\mathrm{NaOH}$ solutions as precipitators for nickel oxalate $\left(\mathrm{NiC}_{2}\right.$ $\left.\mathrm{O}_{4} \cdot 2 \mathrm{H}_{2} \mathrm{O}\right)$, nickel carbonate $\left(\mathrm{NiCO}_{3}\right)$, and nickel hydroxide $\left[\mathrm{Ni}(\mathrm{OH})_{2}\right]$ powders were used. All precursors were synthesized in aqueous media for both hydroxide and oxalate precursors; in addition to using aqueous solutions, alkaline solutions were used. During the continuous condition of magnetically stirred nickel nitrate solution, the same concentrations of precipitators were added for all precursors. During the precipitation, the suspension was kept at room temperature and stirred constantly $\left(2.5 \mathrm{ml} \mathrm{min}^{-1}\right)$. After precipitated precursors formed, they were held under mother circumstances for $3 \mathrm{~h}$ as aging step. Filtering and washing with distilled water and ethanol for three times were done subsequently for removing repeated ions. After drying at $70{ }^{\circ} \mathrm{C}$ for $24 \mathrm{~h}$, the precursors were then heated in air at 300 and $450{ }^{\circ} \mathrm{C}$ for $2 \mathrm{~h}$. The calcined product was pulverized and used for characterization. The final products were distinguished based on the types of precursors and solvents; nickel oxide nanoparticles obtained via carbonate precursors at two calcination temperatures were labeled: C300, C450, hydroxide precursors: H300, H450, oxalate precursors: O300, O450, and samples of final nickel oxide obtained via oxalate and hydroxide precursors with used ethanol solvent at $450{ }^{\circ} \mathrm{C}$ are labeled orderly OE450, HE450.

The thermal decomposition behavior of the precursor was investigated by thermogravimetric analysis (TG) and differential thermal analysis (DTA) on a Netzsch-STA 1640 thermal analysis device. This analysis was carried out in air at a heating rate of $10{ }^{\circ} \mathrm{C} \min ^{-1}$ up to $700{ }^{\circ} \mathrm{C}$. X-ray diffraction (XRD) patterns were obtained at a scanning rate of $10^{\circ} \mathrm{min}^{-1}$ with $2 \theta$ ranging from $10^{\circ}$ to $80^{\circ}$ using a fully automated Philips diffractometer using a $\mathrm{CuK}_{\alpha}$ $(0.15406 \mathrm{~nm})$ radiation source. Individual XRD peak profiles belonging to (110), (200), (220), (311), and (222) planes were extracted, and the optimum linear combinations of Cauchy and Gaussian type functions were fitted to the peak profiles after background removal. Rachinger's correction was carried out to resolve the $\alpha_{1}-\alpha_{2}$ doublets,
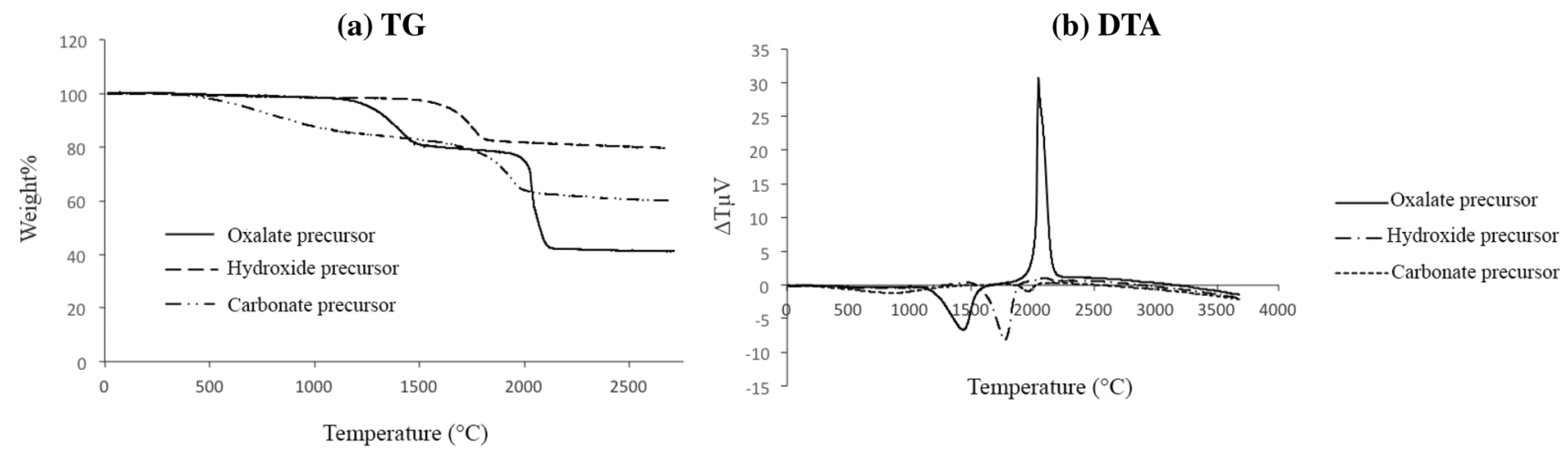

Fig. 1 a, b TG/DTA results of thermal decomposition of three precursors done in the air 
Fig. 2 TG/DTA results of thermal decomposition of $\mathbf{a}$ oxalate and $\mathbf{b}$ hydroxide done in the air for two kinds of solvents: aqueous and ethanol

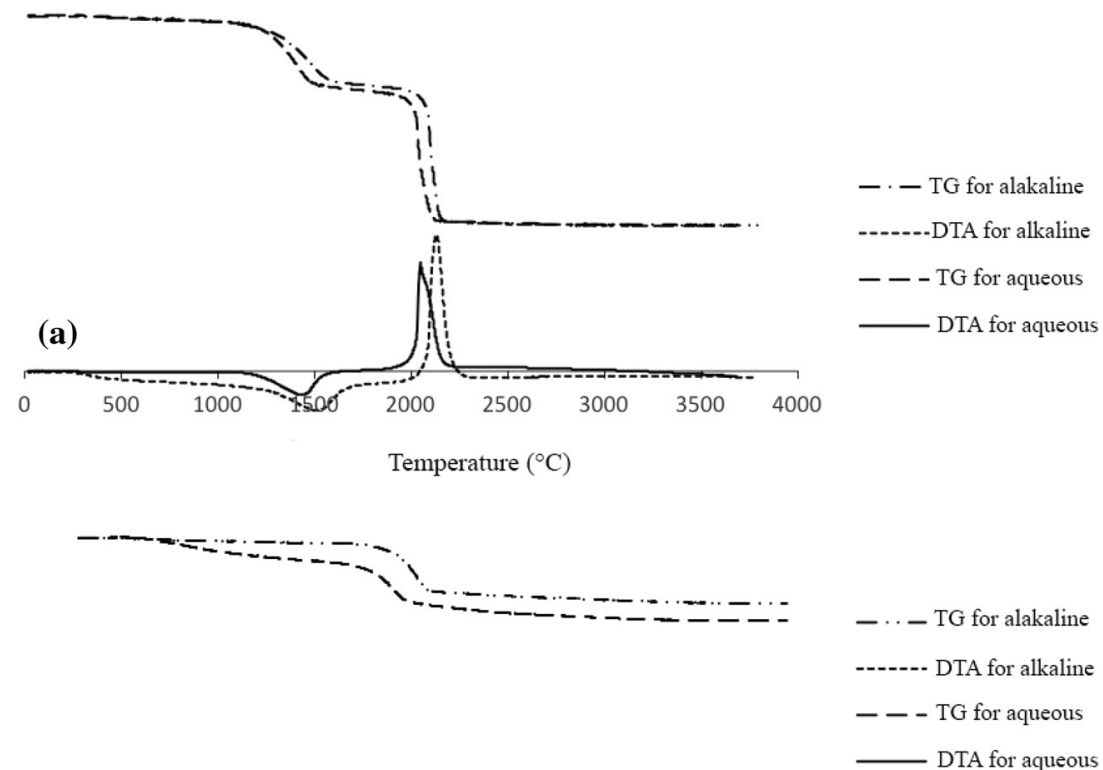

(b)

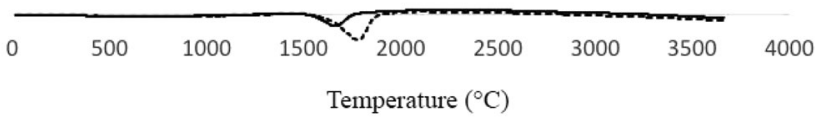

accordingly (Warren 2007). Data from the peak profile were analyzed with classic Williamson-Hall method, and particles size was determined. The morphologies and dimensions of the product particles were observed by field emission scanning electron microscopy (FESEM) using acceleration voltage of $30 \mathrm{kV}$ (S-4160 Hitachi) and transition electron microscopy (TEM) on a PEG CM200 transition electron microscope using an accelerating voltage of $100 \mathrm{kV}$. The data of specific surface area are measured by BET using nitrogen adsorption isotherms at $77 \mathrm{~K}$ by Belsorpmini surface analyzer. The magnetic properties of the particles were measured at room temperature using a vibrating sample magnetometer (VSM) in a maximum applied field of $8 \mathrm{kOe}$.

\section{Results and discussions}

The precursors of nickel oxide nanoparticles were appropriately precipitated via three reactions under solution circumstances as follows.

$$
\begin{aligned}
& 2 \mathrm{H}_{2} \mathrm{O}+\mathrm{C}_{2} \mathrm{O}_{4}^{2-}+\mathrm{Ni}^{2+} \rightarrow \mathrm{NiC}_{2} \mathrm{O}_{4} \cdot 2 \mathrm{H}_{2} \mathrm{O} \\
& \mathrm{Ni}^{2+}+2 \mathrm{OH}^{-}+x \mathrm{H}_{2} \mathrm{O} \rightarrow \mathrm{Ni}(\mathrm{OH})_{2} \cdot x \mathrm{H}_{2} \mathrm{O} \\
& \mathrm{Ni}^{2+}+\mathrm{CO}_{3}^{-}+x \mathrm{H}_{2} \mathrm{O} \rightarrow \mathrm{NiCO}_{3} \cdot x \mathrm{H}_{2} \mathrm{O}
\end{aligned}
$$

Figure 1 shows the TG/DTA results of thermal decomposition of three precursors in air. The decomposition process consists of two steps: The first step is the dehydration of the sample and second is thermal decomposition. Figure 1a shows the TG analysis, in which two decreasing processes are obviously discernible, the first one is in the range of 50 till $250{ }^{\circ} \mathrm{C}$ due to weight losing of physical water, crystalline water, and humidity in pores, and the second one is attributed to $\mathrm{NiO}$ decomposition procedure that varies according to precursors.

The amounts of weight losing of hydroxide precursor are less than other two precursors. The DTA analysis of three precursors (Fig. 1b) shows two peaks related to the dehydration and decomposition processes. The decomposition of hydroxide precursor starts at lower temperature, which is due to the nominal possession of excessive ions exist in the structure of hydroxide precursor. On the other hand, the observed exothermic peak in DTA of oxalate precursors indicates a unique nature of decomposition process for this precursor; which could be due to the simultaneous decomposition of the anhydrous oxalate and oxidation of metallic nickel (Malecka et al. 2007).

Figure 2 shows the heat treatment of two precursors with different solvents. For both precursors, the amounts of weight losing in alkaline solvents are less than aqueous solution while the decomposition of alkaline precursors begins later. Taking this into account, it can be concluded that the type of solvent affects chemically on surface absorption properties of precursors formed in solution such as hydrogen bonding of adjacent particles and formation of particle chains, in which aggregation phenomena can be resulted. 


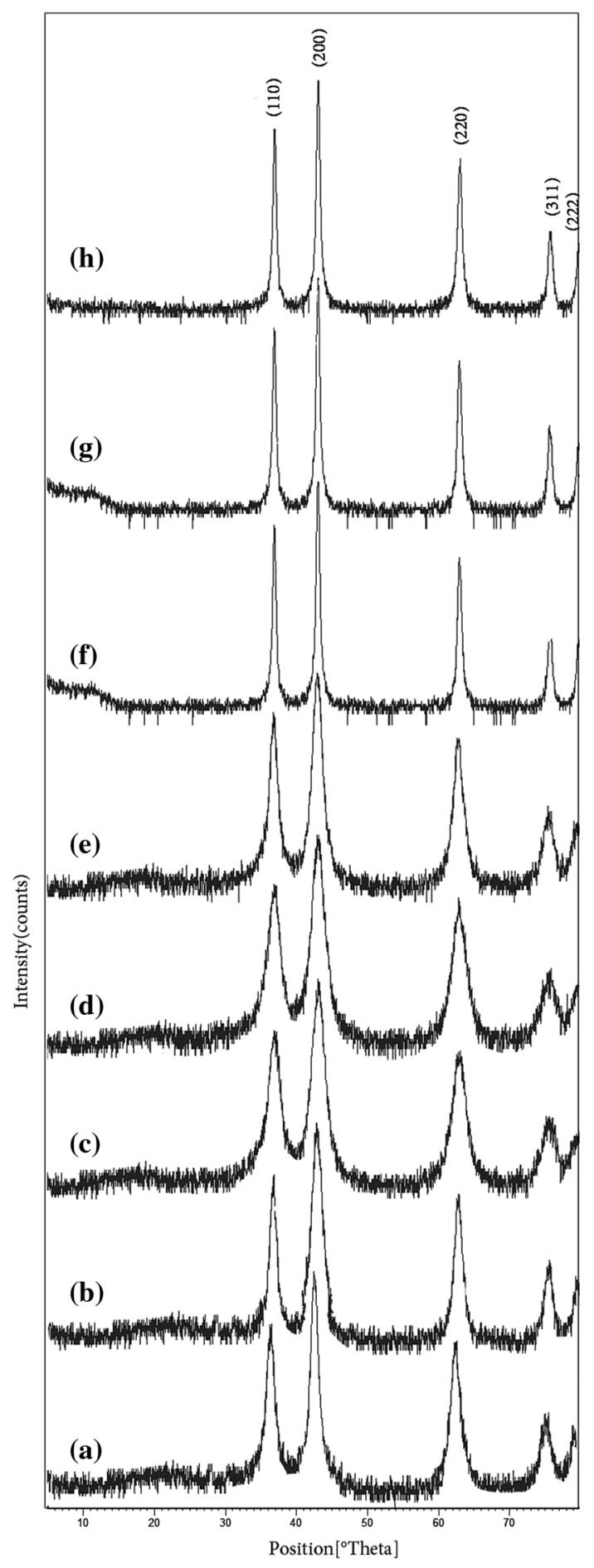

Fig. 3 X-ray diffractogram of prepared nickel oxide nanoparticles. $a \mathrm{C} 300, b \mathrm{H} 300, c \mathrm{O} 300, d \mathrm{HE} 300, e$ OE $300, f \mathrm{C} 450, g$ H450, $h \mathrm{O} 450$

Figure 3 shows the XRD pattern of nickel oxide nanoparticles prepared by the chemical route. The product is a single-phase $\mathrm{NiO}$ with a cubic structure; the diffraction data are in good agreement with JCPDS card of $\mathrm{NiO}$ (JCPDS 01-1239). No impurity peaks were observed in the XRD patterns.
As shown in Fig. 3a-c, within the order of carbonate-, hydroxide-, and oxalate-based precursors, the intensity and sharpness of all the reflections in the XRD pattern of $\mathrm{NiO}$ decrease, which indicates that $\mathrm{NiO}$ obtained via oxalate precursor is poorly crystallized. The broadening effect of $\mathrm{NiO}$ obtained via oxalate precursor may be attributed to the crystallite sizes and increased degree of disordering owing to the existence of crystalline defects and adsorption of inorganic anions (Song et al. 2002). Alkaline solvents have also effect on the peak width especially for sample prepared by hydroxide precursor, by which crystallite sizes are shifted to lower value (Fig. 3d, e). Figure 3f-h reveals that increasing calcination temperature to $450{ }^{\circ} \mathrm{C}$ causes all the reflection peaks become sharper, which suggests the crystallite size and crystallinity of as-calcined $\mathrm{NiO}$ increase with increasing calcination temperature.

Crystallite size of synthesized $\mathrm{NiO}$ powder was measured by using the Williamson-Hall formula, which is given by Eq. 4 (Czichos et al. 2006).

$\beta=\frac{1}{d}+2 \varepsilon K$

where $\beta$ is the integral width of the peaks, $\mathrm{d}$ is the particle size, $\varepsilon$ is the lattice distortion, and $K$ is the diffraction vector. Table 1 displays the crystallite sizes measured by $\mathrm{XRD}$ analysis and specific surface area values according to the BET measurements for particle sizes with assuming spherical shape. Crystallite and particle sizes increase with increasing the temperature; also using ethanol as solvent and heat treatment at $300{ }^{\circ} \mathrm{C}$, particle sizes below $10 \mathrm{~nm}$ can be achieved. All data are in good agreement with the XRD peak patterns.

The surface morphology of nickel oxide nanoparticles at two calcination temperatures is shown in Fig. 4. The FESEM images indicate that $\mathrm{NiO}$ powder has been prepared with spherical shape. As shown in Fig. 4, increasing annealing temperature causes nanoparticles to dwell in well-suited places with homogeneous distribution. Lowering annealing temperature, the $\mathrm{NiO}$ particle sizes decrease below $20 \mathrm{~nm}$, at which the agglomeration is an inevitable phenomenon due to the higher specific surface area. The best distribution of samples with suitable uniformity at $450{ }^{\circ} \mathrm{C}$ belongs to the oxalate precursor. The largest particle sizes at both calcination temperatures belong to $\mathrm{NiO}$ particles prepared by carbonate precursor, which is in good agreement with the data of Table 1 .

Figure 5 shows the surface morphology of samples prepared in alkaline solvent. As shown above, the agglomeration of nickel oxide nanoparticles at lower annealing temperature has been amended using ethanol. As shown in Fig. 5, NiO nanoparticles with uniform particle size distribution have been prepared in this work, as 
Table 1 Crystallite and particle sizes of $\mathrm{NiO}$ nanoparticles

\begin{tabular}{lccc}
\hline Samples & $D_{\text {XRD }}(\mathrm{nm})$ & SSA $\left(\mathrm{m}^{2} \mathrm{~g}^{-1}\right)$ & $D_{\text {BET }}(\mathrm{nm})$ \\
\hline O300 & 10.50 & 78.90 & 11.40 \\
H300 & 12.20 & 71.39 & 12.60 \\
C300 & 14.70 & 58.79 & 15.30 \\
O450 & 17.60 & 49.42 & 18.20 \\
H450 & 19.20 & 44.31 & 20.30 \\
C450 & 31.60 & 25.41 & 35.40 \\
OE300 & 6.00 & 149.92 & 7.10 \\
HE300 & 7.50 & 119.94 & 8.20 \\
\hline
\end{tabular}

SSA specific surface area
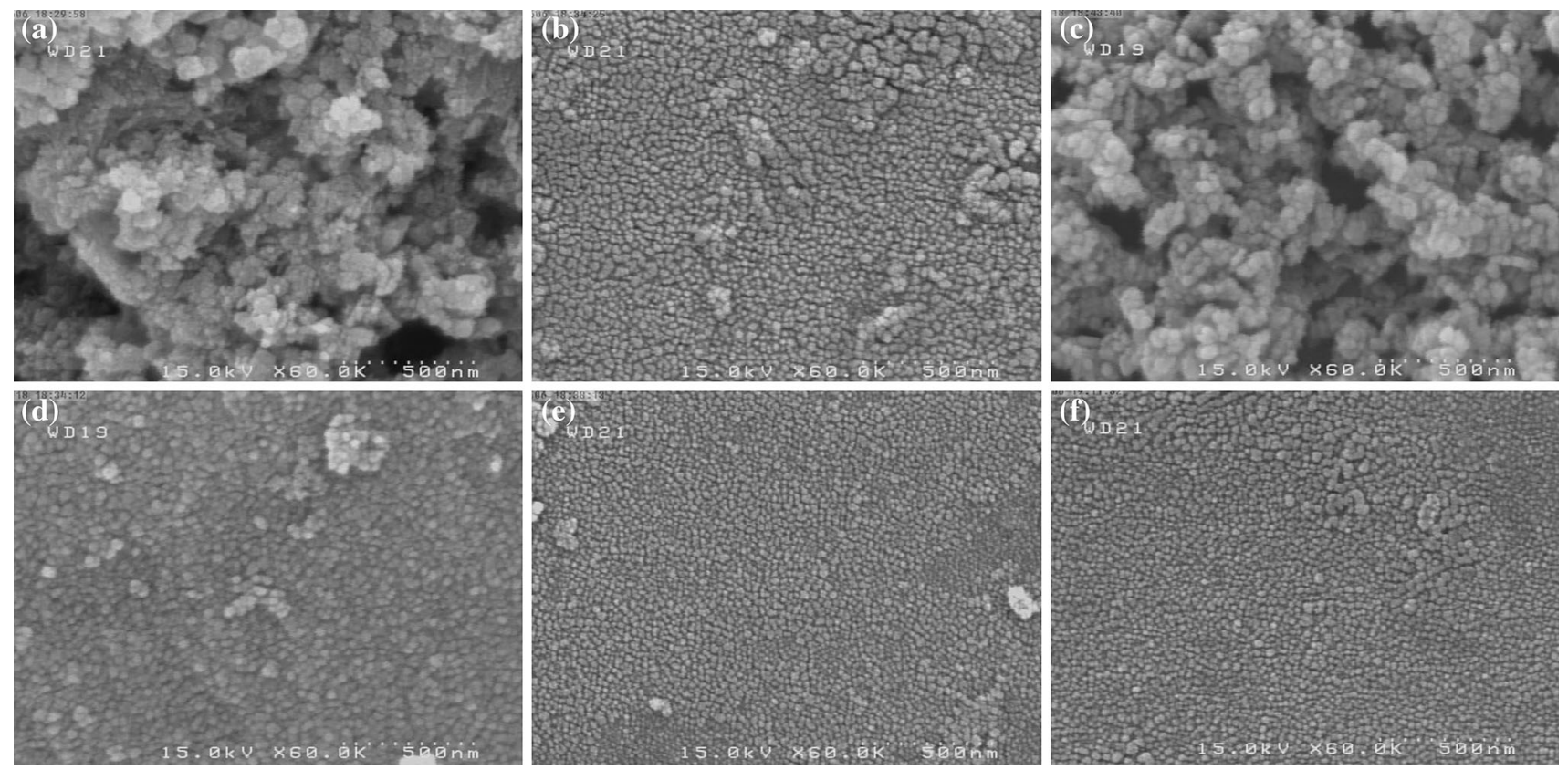

Fig. 4 FESEM images of prepared nickel oxide nanoparticles a O300, b H300, c C300, d O450, e H450, f C450
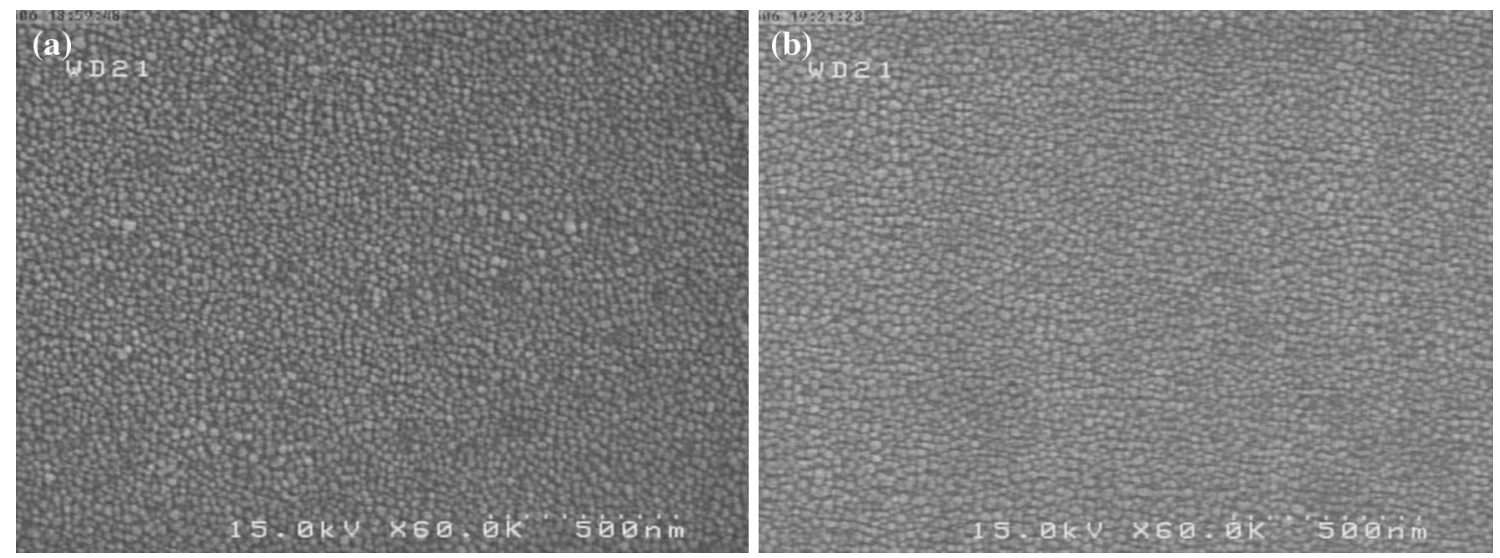

Fig. 5 FESEM of NiO nanoparticles a OE300, b HE300




compared to the results obtained in other investigations (Xiang et al. 2002; Estelle et al. 2003).

The average size of nickel oxide nanoparticles of OE300 as can be observed in the TEM image is below $10 \mathrm{~nm}$. Inset in Fig. 6 shows the electron diffraction pattern of the selected area of nanoparticles. The appearance of strong diffraction spots rather than diffraction rings confirmed the formation of crystalline cubic nickel oxide.

The dispersed particles in the TEM image indicate that the present synthesis method can be considered suitable for preparation of nickel oxide magnetic nanoparticles. One of the key factors for this desired result is the use of organic solvent, i.e., ethanol, instead of water, in which the steric effects presented by ethanol can also prevent aggregation of the individual particles. As mentioned above, the steric effects attribute to physical and chemical surface absorption of ethanol on the surface of the precursor, which resist the formation of particle chains by hydrogen bonding of neighboring particles from aqueous solvent ( $\mathrm{Li}$ et al. 2001).

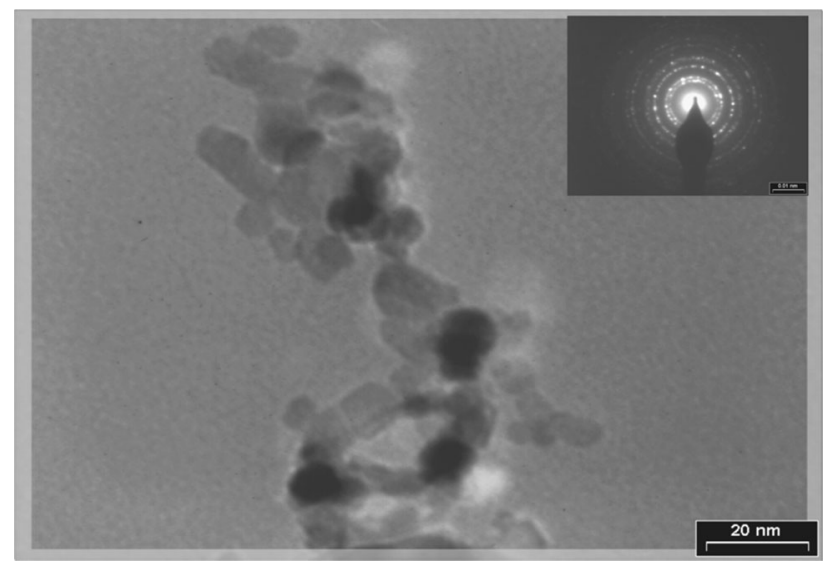

Fig. 6 TEM of the NiO particles. The diffraction pattern is shown in the upper part of TEM picture

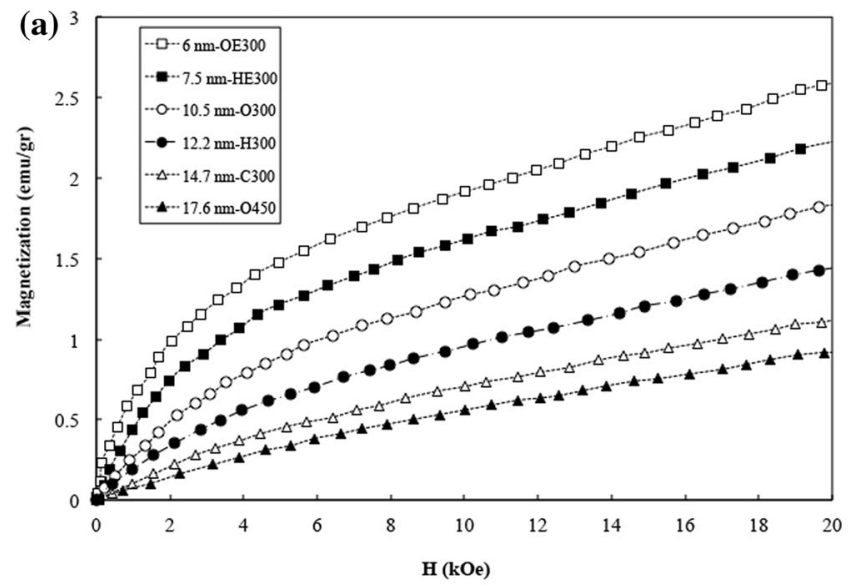

Magnetization curves were measured at ambient temperature for $\mathrm{NiO}$ samples with particle sizes below $20 \mathrm{~nm}$. These plots of $M$ versus $H$ are shown in Fig. 7a for various particle sizes. As shown in Fig. 7a, by decreasing the particle sizes, the magnetization is improved, mainly because of increasing the fractions of surface atoms and the uncompensated surface spins spontaneously, in which higher magnetization is achieved. Among these samples, the $\mathrm{NiO}$ nanoparticles obtained via calcination of oxalate precursor at $300{ }^{\circ} \mathrm{C}(\mathrm{OE} 300)$ with sizes about $6 \mathrm{~nm}$ have maximum magnetization. For this sample, Fig. $7 \mathrm{~b}$ shows magnetic isotherms measured in applied field $H$ up to 20 $\mathrm{kOe}$ at 270,300 , and $320 \mathrm{~K}$. The increase in magnetization with decreasing the temperature is observed.

It is evident that $M$ does not saturate with even $H=20$ kOe where there is a high-field magnetic susceptibility $\chi$. The remanence for OE300 is zero, which is the characterization of superparamagnetic particles. For the larger particles with wider size distributions, a small remanence observed at $H=0$ may be due to the fact that the larger particles are still unblocked at these temperatures.

\section{Conclusion}

Nanocrystalline $\mathrm{NiO}$ was successfully synthesized by employing three kinds of precursors in the media of alkaline and aqueous solutions via precipitation-calcination route, through which by using oxalate precursor and ethanol solvent nanoparticles with average particle size of $6 \mathrm{~nm}$ with narrow size distribution and low agglomeration were achieved. The magnetic characterizations show these particles are superparamagnetic in room temperature and increasing the temperature deteriorates their magnetic properties.

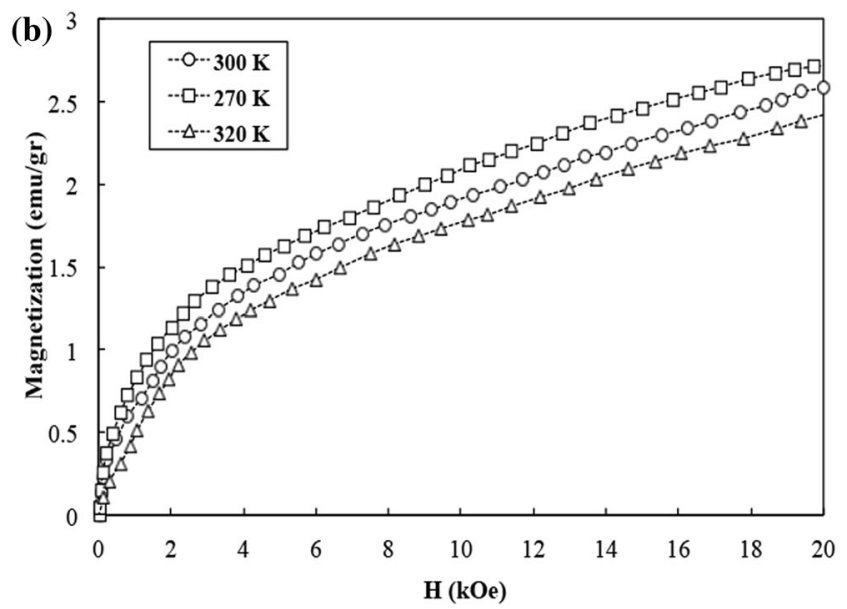

Fig. 7 a Plot of $M$ (magnetization) versus $H$ (applied field) measured at ambient temperature for all samples. b Isothermal plots of the $M$ against $H$ for OE300 at temperatures shown 
Acknowledgments The authors thank Dr. K. Ahmadi for materials analysis and S. B. Ghaffari for useful scientific guidance. This work was supported by Materials and Energy Research Center (No. 378868).

Open Access This article is distributed under the terms of the Creative Commons Attribution 4.0 International License (http:// creativecommons.org/licenses/by/4.0/), which permits unrestricted use, distribution, and reproduction in any medium, provided you give appropriate credit to the original author(s) and the source, provide a link to the Creative Commons license, and indicate if changes were made.

\section{References}

BahariMollaMahaleh Y, Sadrnezhaad SK, Hosseini D (2008) NiO nanoparticles synthesis by chemical precipitation and effect of applied surfactant on distribution of particle size. J Nanomater. doi:10.1155/2008/47059

Chen ZQ, Zhang J (1998) Size-dependence supperparamagnetic properties of $\mathrm{MgFe}_{2} \mathrm{O}_{4}$ spinel ferrite nanocrystallistes. Appl Phys Lett 73:3156

Cullity BD, Graham CD (2009) Introduction to magnetic materials, 2edn. Wiley IEEE Press, New York

Czichos H, Saito T, Smith L (2006) Springer handbook of materials measurement methods. Springer, Berlin

Estelle J, Salagre P, Cesteros Y, Serra M, Medina F, Sueiras JE (2003) Comparative study of the morphology and surface properties of nickel oxide prepared from different precursors. Solid State Ion 156:233-243

Faraji M, Yamini Y, Rezaee M (2010) Magnetic nanoparticles: synthesis, stabilization, functionalization, characterization, and applications. J Iran Chem Soc. doi:10.1007/BF03245856

Gleiter H (2000) Nanostructured materials: basic concepts and microstructure. Acta Mater 48:1-29

Jeong U, Teng X, Wang Y, Yang H, Xia Y (2007) Superparamagnetic colloids: controlled synthesis and niche application. Adv Mater 19:33-60

Karthik K, KalaiSelvan G, Kanagaraj M, Arumugam S, Jaya N (2011) Particle size effect on the magnetic properties of $\mathrm{NiO}$ nanoparticles prepared by a precipitation method. J Alloys Compd 509:181-184

Li GJ, Huang XX, Shi Y, Guo JK (2001) Preparation and characteristics of nanocrystalline $\mathrm{NiO}$ by organic solvent method. Mater Lett 51:325-330

Makhlouf SA, Parker FT, Spada FE, Berkowitz AE (1997) Magnetic anomalies in NiO nanoparticles. J Appl Phys 91:5561-5563

Malecka B, Malecki A, Drozdz-Ciesla E, Tortet L, Llewellyn P, Rouquerol F (2007) Some aspects of thermal decomposition of $\mathrm{NiC}_{2} \mathrm{O}_{4} \cdot 2 \mathrm{H}_{2} \mathrm{O}$. Thermochim Acta 466:57-62

Mathew DS, Juang RS (2007) An overview of the structure and magnetism of spinel ferrite nanoparticles and their synthesis in microemulsion. Chem Eng 129:51-65

McHenry ME, Laughlin DE (2000) Nano-scale materials development for future magnetic applications. Acta Mater. doi:10.1016/ S1359-6454(99)00296-7

O'Handley RC (2000) Modern magnetic materials: principles and applications. Wiley, New York

Richardson JT, Milligan WO (1956) Magnetic properties of colloidal nickel oxide. Phys Rev Lett. doi:10.1103/PhysRev.102.1289

Richardson JT, Yiagas DI, Turk B, Forster K, Twigg MV (1991) Origin of superparamagnetism in nickel oxide. J Appl Phys 70:6977-6982

Song Q, Tang Z, Guo H, Chan SLI (2002) Structural characteristics of nickel oxide synthesized by a chemical precipitation route under different $\mathrm{pH}$ values. J Power Sources 112:428-434

Tao D, Wei F (2004) New procedure towards size-homogeneous and well-dispersed nickel oxide nanoparticles of $30 \mathrm{~nm}$. Mater Lett 58:3226-3228

Warren BE (2007) X-ray diffraction. Addison-Wesley, Reading

Xiang L, Deng XY, Jin Y (2002) Experimental study on synthesis of NiO nano-particles. Scr Mater 47:219-224

Yi JB, Ding J, Feng YP, Peng GW, Chow GM, Kawazoe Y, Liu BH, Yin JH, Thongmee S (2007) Size-dependent magnetism and spin-glass behavior of amorphous $\mathrm{NiO}$ bulk, clusters, and nanocrystals: experiments and first-principles calculations. Phys Rev B 76:224402

Zhou GT, Yao QZ, Wang X, Yu JC (2006) Preparation and characterization of nanoplatelets of nickel hydroxide and nickel oxide. Mater Chem Phys 98:267-272 